\title{
Real Time Implementation of the Grid to Analyze the Performance of the Variable Speed Wind Turbine-Generator during Grid Disturbances
}

\author{
Muhammad M. A. S. Mahmoud*, Adnan Sattar \\ Al Hosn Gas, Abu Dhabi, UAE. \\ * Corresponding author. Tel.: +971551885533; email: mmanar@yahoo.com \\ Manuscript submitted October 4, 2015; accepted March 30, 2016. \\ doi: 10.17706/ijcee.2016.8.2.104-116
}

\begin{abstract}
This paper presents a new operational scheme and methodology to analyze the steady-state and low voltage ride through (LVRT) characteristics of a grid connected variable speed wind turbine driven permanent magnet synchronous generator (VSWT-PMSG) using Real Time Digital Simulator (RTDS). This work is also a part of the future power-hardware-in-loop (PHIL) test. VSWT-PMSG uses fully controlled frequency converter (FC) for the grid interfacing. For the sake of detail analysis, determining precise switching frequency, and future PHIL test, the FC is modeled in VSC small time-step of the RTDS. Non-sinusoidal Pulse width modulation (PWM) technique is used in this study by injecting the $3^{\text {rd }}$ harmonics in the reference three phase voltage signals to increase the output voltage of FC. A salient feature of this study is the incorporation of realistic grid, i.e. three phase supply voltage in real time simulation of RTDS/RSCAD to analyze both steady state and LVRT characteristics of grid connected VSWT-PMSG. The supply-voltage signals are subjected with the noise, e.g., voltage notches by the use of non-linear load. Therefore, voltage notching effect is taken into consideration while the controller effectiveness of the FC is examined under different operating conditions. With the incorporation of supply-voltage fluctuations, its influence on the VSWT-PMSG is analyzed with different switching frequencies of the FC. Extensive comparative study is carried out using both ideal and realistic grids.
\end{abstract}

Key words: Frequency converter, permanent magnet synchronous generator (PMSG), voltage source converter (VSC), grid synchronization, RTDS, supply-voltage fluctuations.

\section{Introduction}

Wind energy is playing an important role in the world's renewable energy market nowadays because of its clean and economical characteristics. According to the Global Wind Energy Council (GWEC) 2011 report, total installed capacity of wind power has reached upto240 [GW] till year 2011. The entire world is predicting the growth of wind energy by 14-16\% from the present status till 2020 [1]. It is clear from the given statistics that, in future, a large number of wind farms will be integrated with the existing power system network. Therefore, it is very important to analyze the steady-state characteristics and low voltage ride through (LVRT) issues of the wind farms to fulfill the requirements of the new set of grid codes [2], [3].

Variable speed wind turbine (VSWT) generating systems are getting more popular nowadays as compared to the fixed speed wind turbine (FSWT) generating systems. Among VSWT generating systems, a few types of generators including double fed induction generator (DFIG), permanent magnet synchronous 
generator (PMSG) are commercially available in the market. The direct drive PMSG technology is getting more attention nowadays because of its simpler operation, low cost, permanent magnets instead of filed winding, reduced flux linkage due to large air gaps and no gear box due to its low rotational speed [4]-[9].

VSWT driven PMSG uses the back-to-back voltage source converters (VSC) scheme for the grid interconnection. Pulse width modulation (PWM) technique is widely used to generate the gate pulses for the VSC due to their fixed switching frequency; well defined harmonics spectrum characteristics and low ripple current [10]. There are multiple strategies of PWM but most basic implemented strategy for a 2 level VSC is the "Sine-triangular". It compares the sinusoidal low frequency reference signal with the high frequency carrier waveform [11]. The Over modulation technique of the regular sinusoidal PWM can be obtained by injecting the third (3rd) harmonic in the reference voltages waveform. It increases the output voltage without recourse to Over modulation and without distorting the line-to-line voltage waveforms. This permits up to $15 \%$ increase in the output voltage of the PWM inverter [12], [13]. This Over modulation voltage-gain relation strategy is very much similar to the space vector PWM (SVPWM) due to their similar performance, advantage of eliminating the sideband harmonics and low total harmonic distortion (THD) [14]-[16].

This study is performed in real time environment by the usage of the real time digital simulator (RTDS) to perform steady-state and LVRT characteristics of VSWT driven PMSG. This study also plans the future power hardware-in-loop (PHIL) testing of VSWT-PMSG to validate the control scheme. RTDS is a novel simulation tool used to run the simulation in real time. It consists of customized parallel processing hardware and a graphical user interface called RSCAD. RTDS provides the facility of interfacing of the real world physical devices and thus can be used for the protection and control system equipment testing before putting them in service for the real power system network. RTDS is being extensively used by the industry and researchers for the advance study and research of the future power system network, i.e., smart grid, distributed generation, renewable energies and advance power electronic technologies [17]-[21].

There is not much work reported to analyze the steady-state and LVRT characteristics of the VSWT-PMSG by using the RTDS simulator. LVRT characteristics of the VSWT-PMSG is analyzed in [22]-[24] using the RTDS simulator by the controller hardware-in-loop (CHIL) method. The controllers of the PMSG back-to-back converters are modeled outside the RTDS environment and are interfaced with the RTDS through the I/O cards. However, the objective was voltage transient testing by using CHIL, therefore less attention has given on the detail LVRT characteristics.

In this work, the grid is considered in the real time named "Realistic grid" and is synchronized with the RSCAD simulation through the Optical analogue to digital converter (OADC) card of the RTDS. PMSG model available in the RSCAD small time-step library is used in this work, beside that machine side inverter, DC link, braking chopper and the grid side converter are modeled in the VSC small time-step environment to adopt with better switching frequency. Over modulation PWM technique is used in this study for the better performance of the VSWT-PMSG during the abnormal grid conditions. Voltage harmonics are injected in the supply-voltage signals and thus three different cases of the realistic grid are considered on the bases of the voltage notching effect. Steady-state and LVRT characteristics and comparative study is performed for the different realistic grid cases and ideal grid.

\section{Modeling of the Variable Speed Wind Turbine Generator System}

\subsection{Magnet Synchronous Generator Model}

The stator of the motor consists of the three-phase windings. The winding produces sinusoidal distribution of magneto motive force which is based upon the value of the current flowing in the stator. The magnets are placed on the surface of the motor core. Their operation is similar to the operation of the field 
winding in a synchronous machine except that their magnetic field is constant and there is no control on it [25], [26].

\subsection{Wind Turbine Modeling}

When you submit your final version, after your paper has been accepted, prepare it in one-column format, including figures and tables. Mechanical power extracted from the wind can be expressed by the following mathematical equation [27], [28].

$$
P_{w}=0.5 \rho\left(\pi R^{2}\right) C_{p}(\lambda, \beta) V^{3}
$$

where $P_{w}$ is the extracted power from the wind, $\rho$ is the air density in $\mathrm{kg} / \mathrm{m}^{3}, R$ is the blade radius in meters and $C_{p}$ is the power co-efficient which is a function of both tip speed ratio, $\lambda$ and the blade pitch angle $\beta$. For calculation of $C_{p}$, for the given values of $\beta$ and $\lambda$ following numerical approximations has been used.

The wind speed is changing continuously, therefore in VSWT the rotational speed of the wind turbine is controlled so that it can track the maximum power point algorithm. It is generally difficult to measure the precise wind speed, therefore the maximum power $P_{\max }$ is calculated by using the optimum values of the power co-efficient, $C_{p}$ and tip speed ratio, $\lambda$ which are 5.9 and 0.44 respectively, without measuring the wind speed by using the equation 2 ,

$$
P_{\max }=0.5 \rho \pi R^{5} \frac{C_{p \_m a x}}{\lambda_{o p t}{ }^{3}} \omega_{r}^{3}
$$

The characteristic of the VSWT adopted in this study is shown in Fig. 1. Note that the dotted line represents the maximum captured power as iaaat has to be limited at higher wind speeds [6].

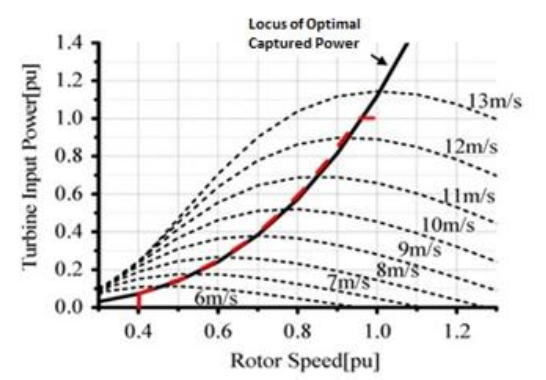

Fig. 1. Wind turbine characteristic.

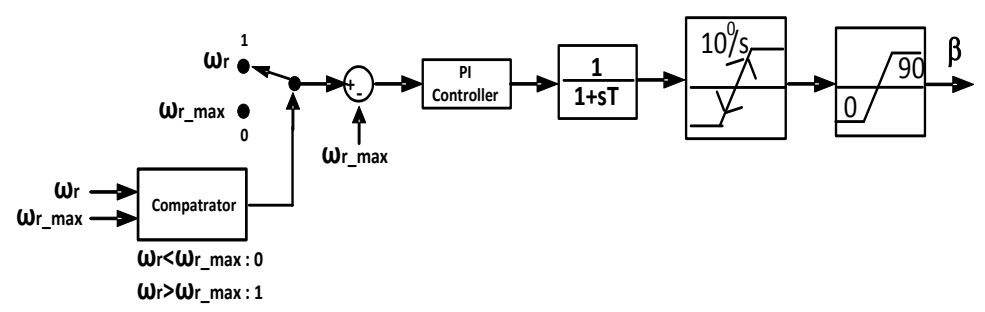

Fig. 2. Pitch angle controller.

In variable speed WTGSs pitch controller is also to control the rotational speed when the reference power is greater than the rated power of PMSG. The range of the rotor speed variation is approximately from 5 rpm to $16 \mathrm{rpm}$. Threshold value of rotor speed can easily be determined from the turbine characteristics. Therefore, the reference power will not exceed the rated power of the PMSG [29]. Fig. 2 shows the block diagram of the pitch angle controller. 


\section{Experimental Setup Using Real Time Digital Simulator (RTDS)}

\subsection{RTDS Overview}

RTDS is based upon the combination of advance computer hardware and widespread software. It has a parallel processing architecture hardware assembled in the modules, called Racks. Each rack consists of the processor cards and communication cards which are linked by a common backplane. The RTDS has a graphical user interface, named RSCAD, which allows the user's interface with the hardware. It also allows the user to construct the simulation circuit, run, operated, and results to be recorded. RSCAD consist of multiple modules like Draft, RunTime, T-LINE, Multi-plot, Cable, and C-Builder (component builder) [30]-[32].

RTDS hardware consists of number of different types of processing and communication cards. Processing cards are Tripple Processor Card (3PC), RISC Processor Card (RPC), and Gigabyte Processor Card (GPC). It is noted that the RTDS latest generation of processor card, PB5 is now available in the market. 3PC processor card contains three analogue devices (SHARC) processor operating at $80 \mathrm{MHz}$. 3PC is normally used to solve the power system module and control system with the typical time-step of $50 \mu \mathrm{sec}$. The RPC card contains two IBM POWERPC RISC processors which operates at 600MHz. GPC contains two IBM POWERPC RISC processor operates at $1 \mathrm{GHz}$. The most recent and powerful card among all other cards are PB5, it consist of two POWERPC RISC processor operating at $1.7 \mathrm{GHz}$. For the network solution and simulation for the standard component, the GPC is used in this work. It provides small-time step $(1 \mu \mathrm{sec}<4 \mu \mathrm{sec})$ simulation of the VSC with high switching frequency. Besides that, RTDS also provides special small-dt feature to perform the small time-step simulations on the GPC card [33].

Digital and analogue signals can be interfaced with the RTDS through the digital optical isolation system (DOPTO) and optical isolated analogue to digital converter (OADC) card respectively. 24 digital input and output signals can be interfaced between the external equipment and RTDS through DOPTO. It normally operates at $5 \mathrm{~V}$ but can be used up to $24 \mathrm{~V}$ with external voltage source. OADC has 6 optically isolated 16-bit analogue to digital converter. It is compatible with the 3PC card and allows the analogue signal range up to $\pm 10 \mathrm{~V}$.

\subsection{System Modeling and Processor Assignment}

The model system use in this study is shown in Fig. 3. Here, one PMSG is connected to the grid through the machine side converter, DC link capacitor, grid side converter and a double circuit transmission line.

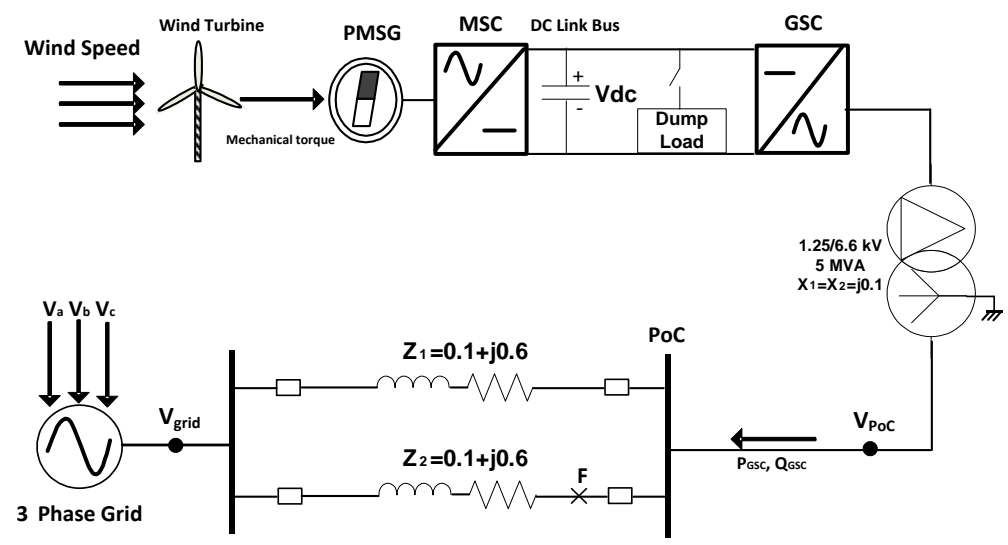

Fig. 3. System model block diagram.

In the Fig. 4, RTDS modules and processor assignments are shown. PMSG machine model, machine side converter, DC link, braking chopper and grid side converter are modeled in the VSC small time-step which is 
solved in the GPC card. The controllers associated with the inverter/converter are modeled in the large time-step and are solved on the 3PC card. Transmission line and grid are modeled in the large time-step and are solved on the 3PC card. The VSC large time-step and small time-step are interfaced through the Interface transformer. The VSC small time-step is $2.7 \mu \mathrm{sec}$ and VSC large time-step is $50 \mu \mathrm{sec}$.

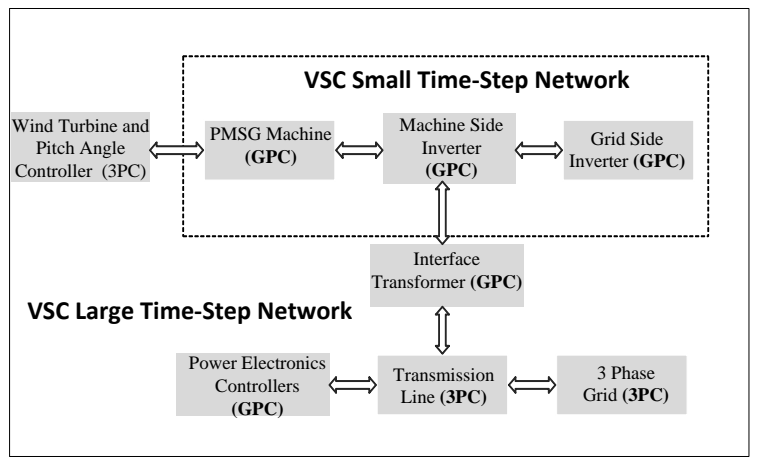

Fig. 4. RTDS modules and processor assignments for the VSWT-PMSG.

\subsection{Integration of Realistic Grid with RTDS}

As explained before, a salient feature of this paper is the introduction of the Realistic Grid. Fig. 5 shows the real time simulation setup. It shows the 3-phase voltage supply along with the rectifier, RL load and voltage probes. Interfacing of the grid signals with the RSCAD is done by the OADC card of the RTDS as shown in Fig. 5.

The three instantaneous voltage signals are captured, scaled suitably, and used in simulation study to form the realistic grid. The objective is to examine the possible effects of the non-idealities on the grid on the VSWT-PMSG wind generator performance. On introducing the voltage waveforms, it was noticed that the residential grid of Abu Dhabi city enjoys a very clean supply.

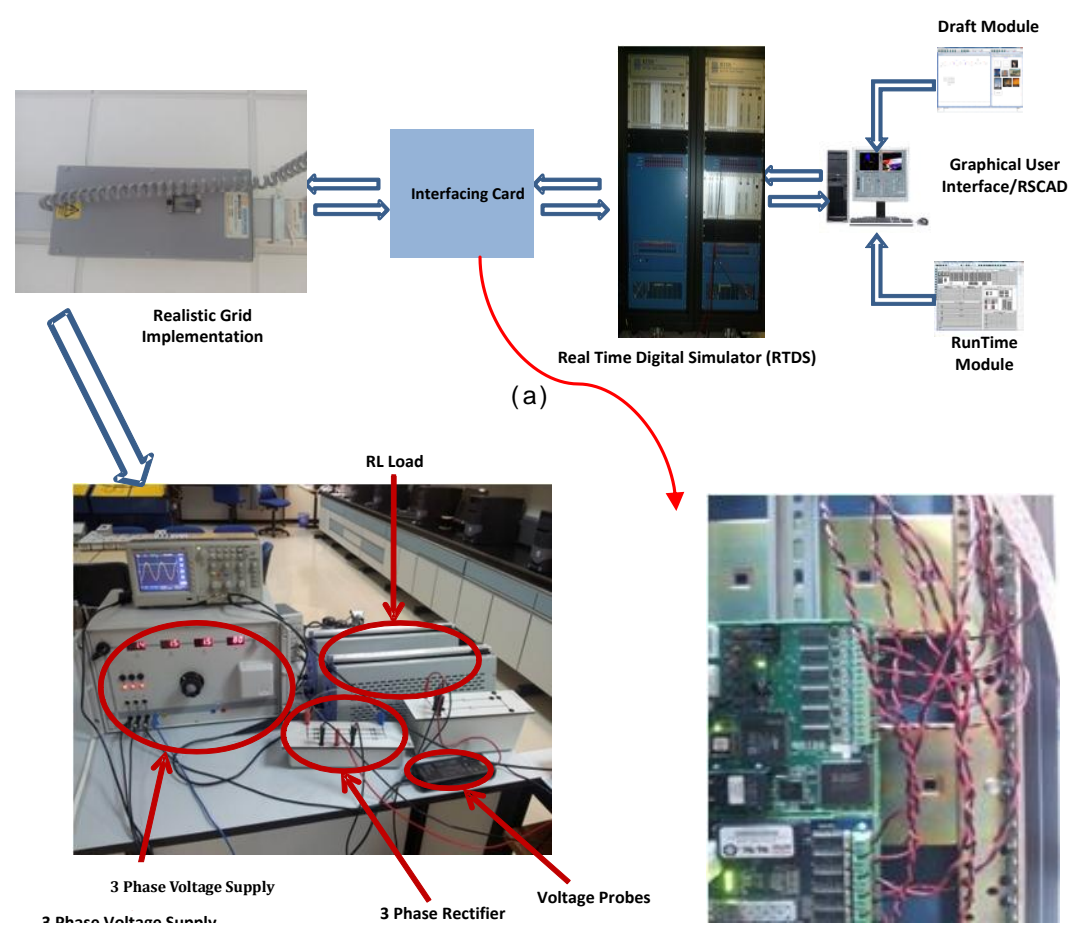

Fig. 5. (a) Real time simulation setup (b) Implementation of the realistic grid along with non-linear load (c) Optical analogue to digital conversion (OADC). 
As this is not a common case, especially for industrial supplies, it was opted to introduce a simple non-linear load and use the resulting voltage waveforms. The realistic grid used in the simulation is calibrated before each run by adjusting the scaling factors to obtain the desired peak voltage on Phase A. The same factors are then used for the other two phases. Three different cases for the realistic grid are considered as shown in Fig. 6 . Case 1 is considered with the voltage wave shapes having no harmonic components, i.e., Green, Case 2 is considered when the voltage wave shapes are affected with the harmonics with the non-linear load of $100 \Omega$, i.e., Black, and Case 3 is considered with the voltage wave shapes having harmonics with the non-linear load of $130 \Omega$, i.e., Red. The parameter of the PMSG used in this study is shown in Table 1.

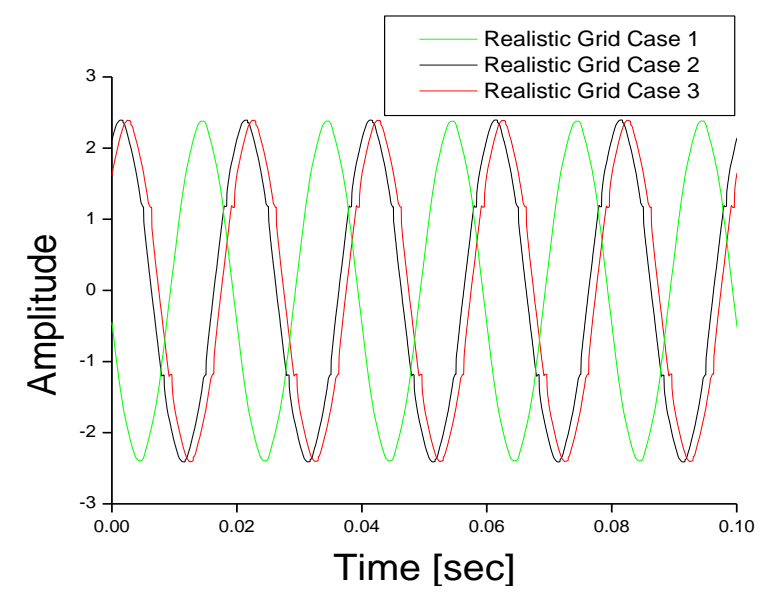

Fig. 6. Voltages waveforms captured from the realistic grid.

Table 1. PMSG Parameters

\begin{tabular}{ccc}
\hline \hline Parameters & \multicolumn{2}{c}{ Rating } \\
\hline Rated Power & \multicolumn{2}{c}{$5 \mathrm{MW}$} \\
Rated Voltage & 1.0 & {$[\mathrm{kV}]$} \\
Frequency & 20 & {$[\mathrm{~Hz}]$} \\
d-axis Reactance & 1.0 & {$[\mathrm{pu}]$} \\
q-axis reactance & 0.7 & {$[\mathrm{pu}]$} \\
H & 3.0 & {$[\mathrm{sec}]$} \\
Number of Poles & 150 \\
Stator Resistance & $0.01[\mathrm{pu}]$ \\
Field Flux & \multicolumn{2}{c}{$[\mathrm{pu}]$} \\
\hline \hline
\end{tabular}

\section{Modeling of the Frequency Converters}

In this study, direct driven PMSG is connected to the grid through fully controlled frequency converters (FC). The FC is composed of 2-level voltage source converter, called machine side inverter (MSI) and grid side converter (GSC), are connected back-to-back.

\subsection{Machine Side Converter (MSI)}

The machine side inverter is connected with the stator of the PMSG which efficiently decouples the PMSG to the grid, thus allowing the rotor of the wind turbine and generator to rotate freely depending on the wind speed conditions.

Well know cascaded vector control scheme is used to control the real and reactive power of the PMSG. The three phase electrical and dq quantities are dependent on each other by the rotor reference frame. Park 
transformation is used for the reference frame transformation. The transformation angle $\theta \mathrm{r}$ is calculated by integrating the rotor speed of the generator. As the MSI is connected directly with the PMSG, therefore active power is controlled by the $\mathrm{q}$ axis current component. The reference for the active power is calculated such that it can follow the MPPT and extract the maximum power from the wind energy. During the network disturbance, the grid voltages decreases significantly, therefore it is not possible to deliver the extracted power to the grid. Therefore, the reference power is varied accordingly when the grid voltages drop to $0.9 \mathrm{pu}$. The $\mathrm{d}$ axis current component is used to control the reactive power of the PMSG. The reference for the reactive power is set to zero for the unity power factor operation. The control block diagram of the MSI is shown in Fig. 7.

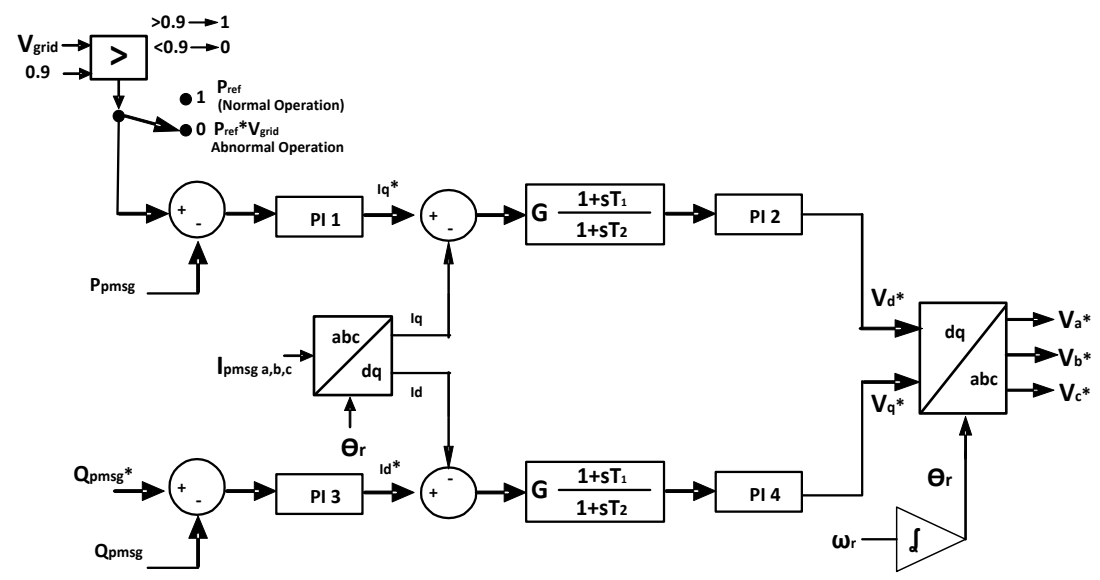

Fig. 7. Block diagram of the machine side inverter.

\subsection{Grid Side Converter (GSC)}

The cascaded vector control scheme shown in Fig. 8 is used to control the grid side converter. The main objective of the control system is to keep the DC link voltage constant and thus ensuring that active power generated by the PMSG is feed into the grid. Secondly, to control the terminal voltage through the reactive power fed or absorb from the grid. The GSC is controlled in the synchronous reference frame. The transformation angle is calculated from the three phase voltages at the high voltage side of the transformer connected at the grid side by using the phase locked loop (PLL).

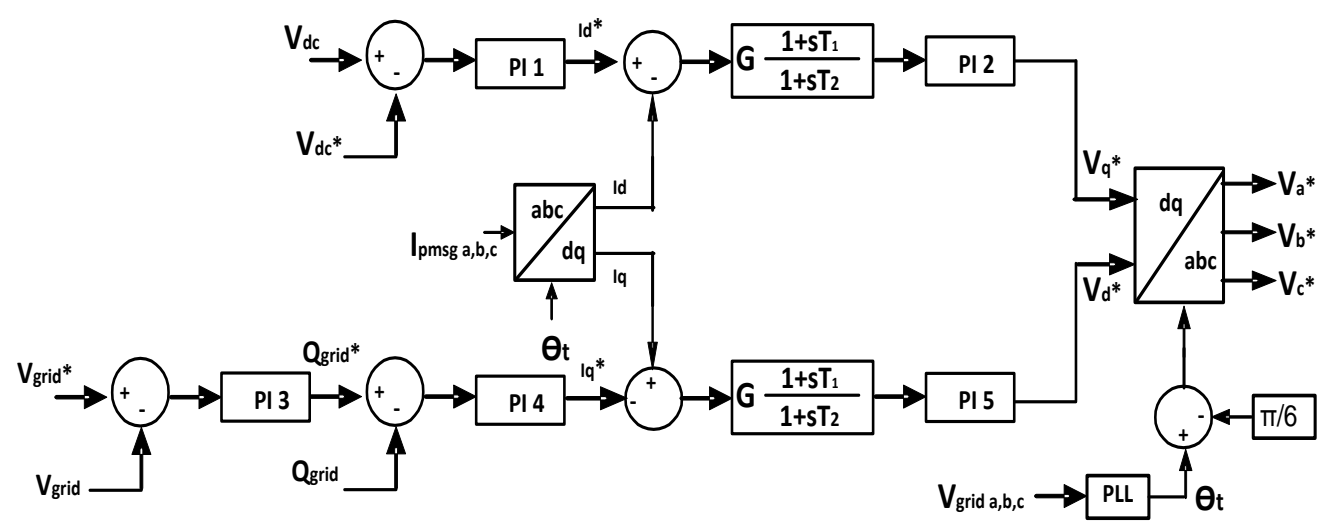

Fig. 8. Block diagram of the grid side converter.

The d-axis current component controls the DC link voltage of the capacitor. Two PI controllers are used to keep the DC link voltage constant. The q-axis current controls the reactive power of the GSC. The reference 
for the reactive power is set such that the terminal voltage at the grid side remains constant. To achieve the control strategy, total three PI controllers are used to control the reactive power of the grid side converter. The additional PI controller in reactive power control gives very good transient characteristics during the grid disturbance. The rated DC link voltage is $2.3 \mathrm{kV}$ and DC link capacitor value is chosen $10,000 \mu \mathrm{F}$.

\subsection{Overvoltage and Under-Voltage Protection of DC Link}

During the severe network disturbance such as 3LG fault, the GSC must be able to supply the additional reactive power in order to support the grid. Thus, it is not possible for the GSC to deliver the active power from the generator to the grid, thus causes the over voltage in DC link, effecting the operation of the frequency converter. In order to overcome the over voltage issue an over voltage protection scheme (OVPS) is needed to avoid this condition. The braking chopper is modeled in the DC link to protect the DC link capacitor during the network disturbance. This chopper gets activated when the DC link voltage increases over the pre-defined limit and absorbs the active power in the resistance during the fault. The hysteresis control is used to control the braking chopper.

Besides overvoltage protection, under voltage protection scheme is also considered in this work. In the GSC, the output of the integrators used in the PI controllers is reset when the DC link voltage drops to a pre-defined value. Only the outer-loop PI controller integrators are reset as in normal practice the inner current control loops are not reset. In this way, the tripping of the generator due to under voltage is avoided during the network fault.

\subsection{Addition of the 3rd Harmonic in PWM Switching Scheme of RSCAD/RTDS}

3rd harmonic is injected in the reference three phase voltage signals obtained from the dq-abc transformation by the following equation,

$$
\text { PWM_TRH }=\frac{-1}{2}\left[\max \left(V_{a}^{*}, V_{b}^{*}, V_{c}^{*}\right), \min \left(V_{a}^{*}, V_{b}^{*}, V_{c}^{*}\right)\right.
$$

The reference signals obtained from the equation (1), (2) \& (3) are used as a new reference and are compared with the carrier wave signals to generate the switching pulses for both MSC and GSC.

\subsection{Switching Scheme in the RTDS}

In order to use the Over modulation technique of PWM, the carrier wave and modulated signals are generated in the large time-step environment of RTDS. The carrier wave and modulated signals are then processed to generate the high resolution firing pulses by the using the firing pulse generator component of RTDS inside the small time-step environment. The firing pulse generator needs the reference phases and frequency from the large time-step to generate the precise firing pulses. The GTO bridge vales get the firing pulses from the comparator inside the small time-step environment. Every valve of the GTO Bridge is controlled by the respective bit in a firing pulse word. The bits are controlled such that the least significant bit (LSB) in the firing pulse word coincides the LSB in the final applied firing pulse word. Thus the first LSB controls the first valve of the GTO bridge, second LSB controls the second valve, third LSB controls the third value and so on [19], [20], [33].

\section{RTDS Results and Discussions}

This section presents the real-time simulation results of the grid connected VSWT-PMSG. Steady state and LVRT characteristics of the VSWT-PMSG for the ideal and realistic grid are analyzed. The section is divided into two parts. In the first part, the steady state characteristics are analyzed using ideal grid and realistic grid. In the second part, LVRT characteristics are analyzed by considering the real grid codes. 


\subsection{Steady State Characteristics Analysis}

For steady state characteristics analysis, it is assumed that the wind speed is constant and equivalent to the rated speed of the VSWT-PMSG. For the detailed analysis, the switching frequency of the back-to-back converters is chosen $1050 \mathrm{~Hz}$. Time step for the VSC small time step and large time step are $2.7 \mu$ sec and 50 $\mu$ sec respectively, and simulation time is chosen 10 seconds.

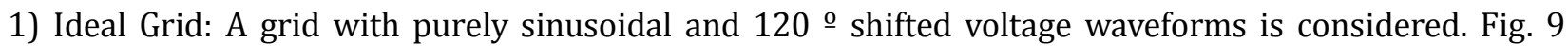
shows the RSCAD simulation result of the one of the grid phase voltage, grid side reactive power, RMS value of grid voltage and grid side real power. In ideal grid, the phase voltage is constant which is also obvious from the RMS value of terminal voltage, and the reactive power support from the grid is $0.07 \mathrm{pu}$.

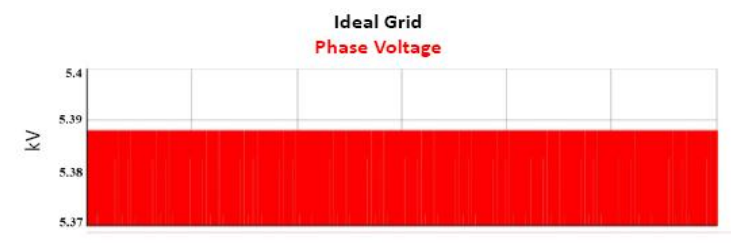

Grid Side Reactive Power

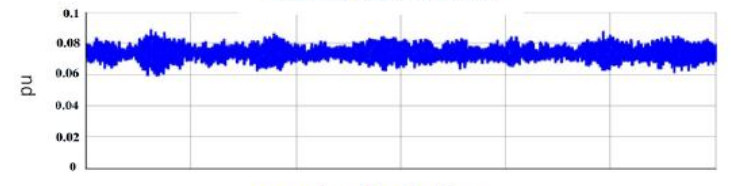

RMS Value of Grid Voltage

ฉે.

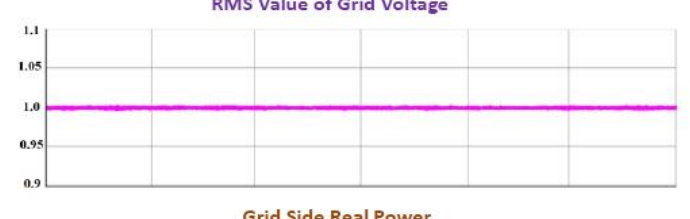

Grid Side Real Power

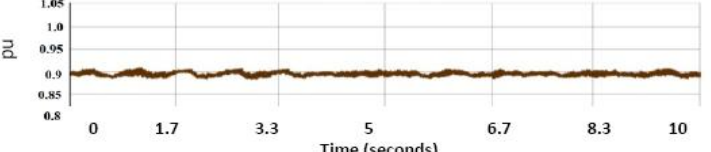

Fig. 9. Responses using realistic grid, ideal grid.
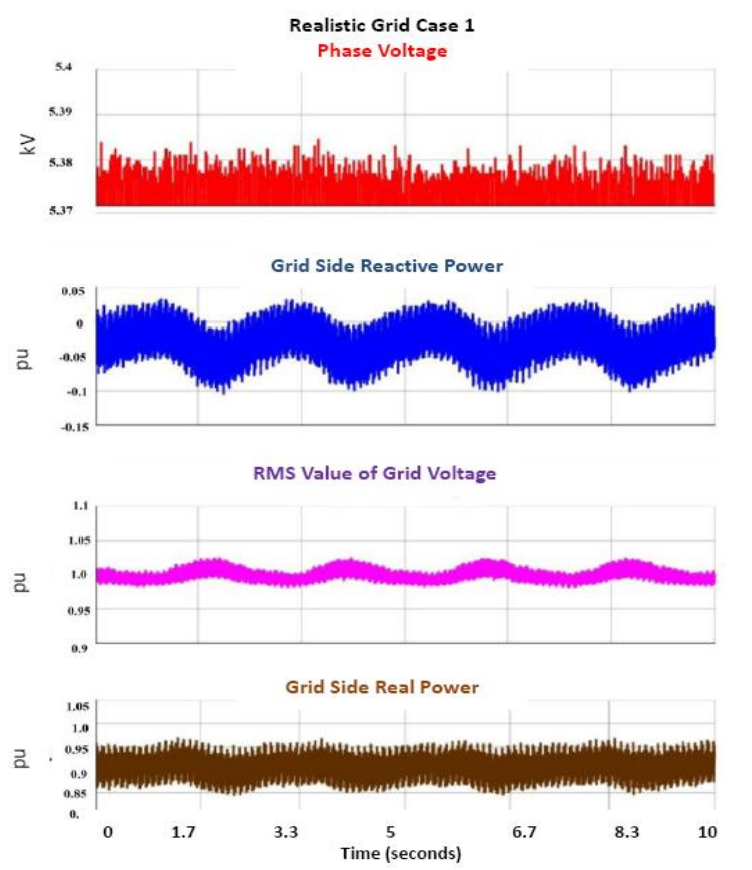

Fig. 10. Responses using realistic grid, Case 1.

2) Realistic Grid: For the realistic grid, three cases are considered as explained earlier in section III-C in Fig. 6 to have a better understanding about steady state characteristics.

Case 1: In this case, grid is controlled from outside by the 3 phase voltage supply. The three phase voltage signals are incorporated with the RSCAD simulation through the OADC card. Fig. 10 shows the simulation results of this case study, where one phase grid voltage signal, RMS value of terminal voltage, reactive power, and real power are shown. Variations of voltage and powers are noticeable in the responses when realistic grid is considered compared to the case of using ideal grid.

Case 2: Non-linear load is considered to be connected with the external circuit. The Resistive Load value is chosen to be 100 Ohms. The voltage harmonics injected are within the IEE 519-1992 limits [34]. These harmonics result in producing the notches in the voltage signals. The simulation results for this case is shown in Fig. 11. In order to overcome the voltage notches, the system required more reactive power support from the system; therefore reactive power is increased to $0.12 \mathrm{pu}$. In order to make system stable, the grid side converter control is adopting itself in realistic operation and trying to maintain the terminal voltage to its rated value.

Case 3: The voltage harmonics is increased by increasing the non-linear load to a 30 percent of full load i.e. $130 \mathrm{ohms}$. As, the result, notching in the 3 phase voltages are increased, thus system is demanding more reactive power to overcome the notching effect, therefore reactive power is increased to $0.26 \mathrm{pu}$, while other 
results remains the same as in case 2. The simulation result of this case is shown in Fig. 12.
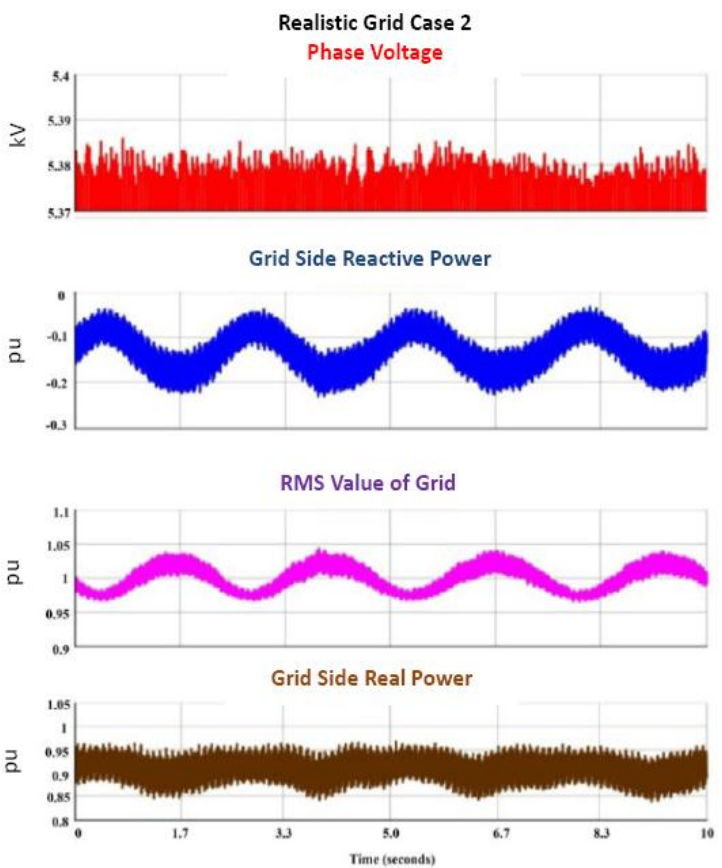

Fig. 11. Responses using realistic grid, Case 2.

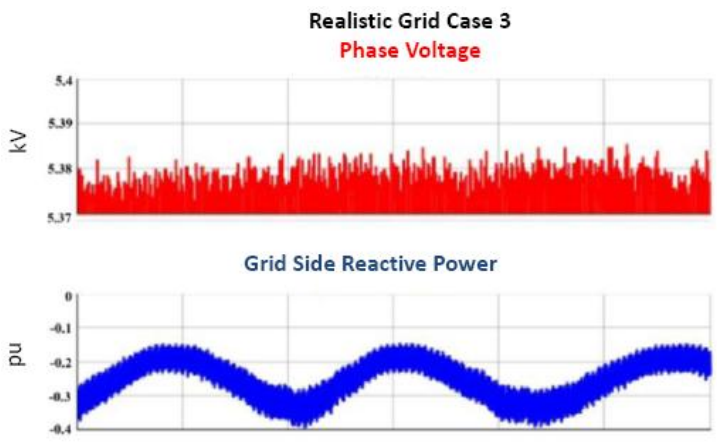

RMS Value of Grid

る

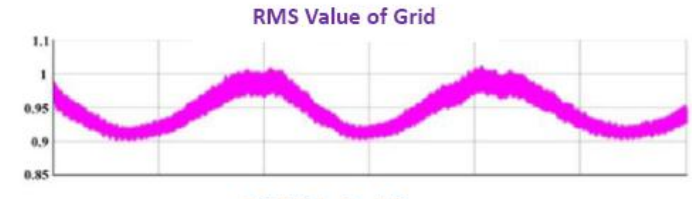

Grid Side Real Power

z

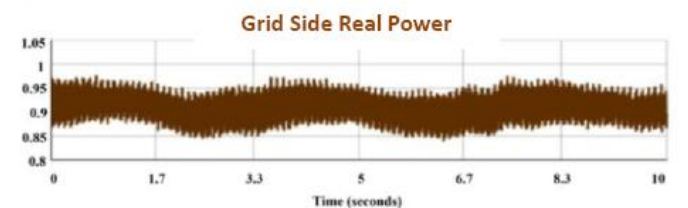

Fig. 12. Responses using realistic grid, Case 3.

It can be understood from Fig. 10-Fig. 12 that incorporation of realistic grid in the simulation helps to know the exact steady state behavior of system variables. Moreover, as the supply-voltage is not constant, therefore the terminal voltage and reactive power is oscillating with respect to the supply-voltage fluctuations. The reactive power demand is increased by increasing the non-linear load to overcome the voltage-supply notching effects.

\subsection{LVRT Characteristics Analysis}
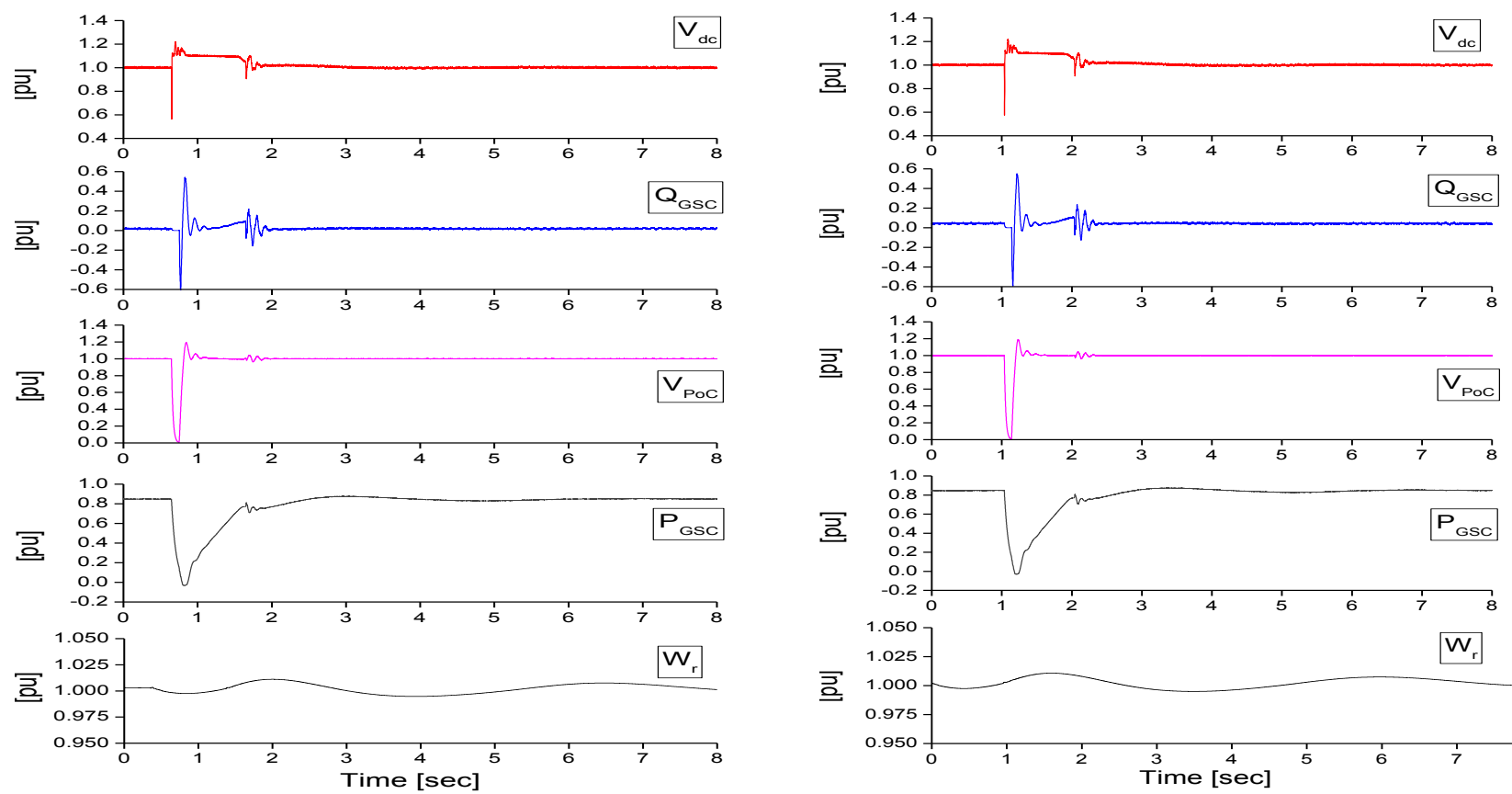

Fig. 13. RTDS LVRT - ideal grid (3LG fault).
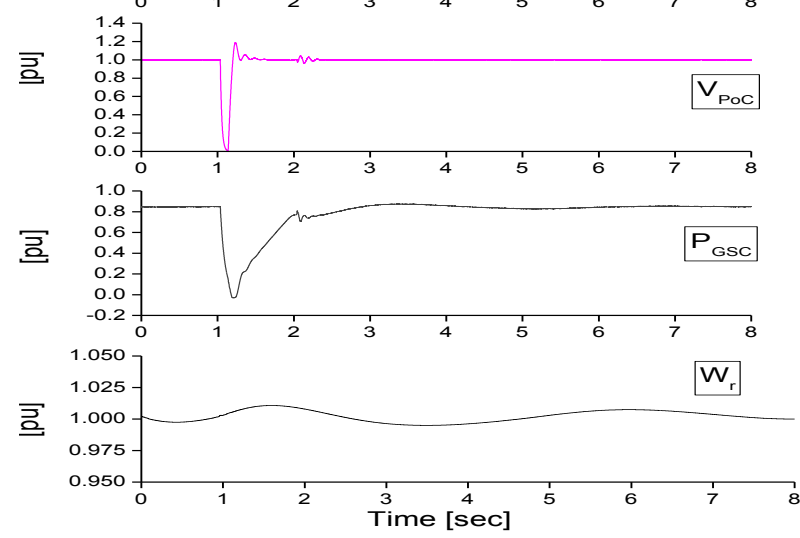

Fig. 14. RTDS LVRT -realistic grid (Case 3, 3LG fault). 
According to the E.ON Netz (rebranded as TenneT TSO GmbH)wind farm grid codes, the plant must stay online when the line voltage drops to zero of nominal voltage for a period less or equal to $150 \mathrm{msec}$ and should recover to $90 \%$ of nominal voltage within 1.5 seconds from the time of the occurrence of the fault [3]. Grid fault causes the voltage sags at the connection point of the wind farm, even if they are at distant location. Theses voltage sags will cause result in imbalance between the input power of wind turbine and the generator output power, DC link voltage fluctuation, and the change in the rotor speed of PMSG. In the simulation, it is assumed that wind speed is constant as mentioned earlier that the wind does not change greatly within the small time duration considered. The switching frequency of the FC is considered to be $1250 \mathrm{~Hz}$. The symmetrical three-line-to-ground (3LG) fault is considered at the sending end of the transmission line. The duration of the fault is $150 \mathrm{msec}$. Circuit breakers are successfully reclosed after 1 second. LVRT characteristics are analyzed for the ideal and realistic grid case 3 only. The responses of the DC link voltage $[\mathrm{kV}]$, real power [pu], reactive power [pu], terminal voltage at PCC [pu], and rotor speed [pu] of the PMSG are shown in Fig. 13 in the case of using the ideal grid. For the realistic grid case 3, (Fig. 14) when the LLLG fault occurs, the system will collapse. To overcome the transient, the system will provide the necessary reactive power support to the system to bring the terminal voltage at 90 percent of its steady state value within $150 \mathrm{msec}$. Besides that, the notching effect in the grid voltage has also overcome.

\section{Conclusion}

This paper presents a detailed study of the VSWT-PMSG in real time digital simulator. Steady state and LVRT characteristics have been analyzed in real time environment, which makes the system more realistic. The modeling of VSWT-PMSG and frequency converters has been done in small time-step, which could be used to any power hardware-in-loop test as it can handle the time-step in the range of $1-4 \mu$ sec. The effect of voltage notching has also been carried out.

During the network disturbance, the grid side converter provides the additional reactive support to the system to overcome the system disturbance. Voltage notching has great impact on system stability; the higher the notching higher the reactive power support from the grid. Real time implementation of the grid helps to examine the effect of the reactive power on the overall system behavior and therefore, can be adopted in the real world operation of the VSWT-PMSG. From the analysis, it is concluded that the switching frequency of the frequency converter is required to be adjusted based on the grid supply voltage fluctuations.

The setup presented in this paper is well suited to allow PHIL experiments for megawatt class wind farm grid interfacing considering realistic grid which eventually overcomes the limitations of current handling capability of RTDS. It is proposed that the realistic grid interfacing methodology with RTDS simulation used in LVRT and steady state characteristics analyses of wind farm can also be used in other renewable energy and smart grid applications along with control validation for industrial products.

\section{References}

[1] The Global Wind Energy Council. (June 2011). Global Wind Report, Annual Market Update 2010.

[2] Hulle, F. V. (Dec. 2005). Large scale integration of wind energy in the European power supply analysis. Issue and Recommendations, Tech. Rep.

[3] OnNetz. (April 2006). Grid Code, High- and Extra-High Voltage. From http://www.eon-netz.com/

[4] Miller, T. J. E. (1989). Brushless Permanent-Magnet and Reluctance Motor Drives. Oxford University Press, New York, United States.

[5] Chinchilla, M., Arnaltes, S., \& Busgos, J. C. (March 2006). Control of permanent-magnet synchronous generators applied to variable-speed wind-energy systems connected to the grid. IEEE Trans. on Energy 
Conversion, 21(1).

[6] Muyeen, S. M., Takahashi, R., Murata, T., \& Tamura, J. (2010). A variable speed wind turbine control strategy to meet wind farm grid code requirements. IEEE Trans. Power Syst., 25(1), 331-340.

[7] Wei, L., Joos, G., \& Belanger, J. (April 2010). Real-time simulation of a wind turbine generator coupled with a battery supercapacitor energy storage system. IEEE Trans. Industry Electronics, 57(4), 1137-1145.

[8] Van Dessel, M., Gay, M., \& Deconinck, G. (2010). Simulation of grid connected PM generator for wind turbines. Proceedings of IEEE 19th Int. Symp. Industrial Electronics (pp. 1497 -1484).

[9] Steurer, M., Edrington, C. S., Sloderbeck, M., Ren, W., \& Langston, J. (April 2010). A megawatt-scale power hardware-in-the-loop simulation setup for motor drives. IEEE Trans. on Ind. Electron., 57(4), 1254-1260.

[10] Houldsworth, J. A., \& Grant, D. A. (1984). The use of harmonic distortion to increase the output voltage of a three-phase PWM inverter. IEEE Trans. Ind. Applicat., 20, 1224-1228.

[11] Bowes, S. R., \& Midoun, A. (1985). Suboptimal switching strategies for microprocessor controlled PWM inverter drives. Proc. Inst. Elect. Eng., 132, 133-148.

[12] Murphy, J. M. D., \& Egan, M. G. (1983). A comparison of PWM strategies for inverter-fed induction motors. IEEE Transactions on Industry Applications, IA-19(3).

[13] Holtz, J. (1992). Pulsewidth modulation - A survey. Proceedings of IEEE PESC'92 (pp. 11-18).

[14] Bowes, S. R., \& Lai, Y. S. (1997). The relationship between space-vector modulation and regular-sampled PWM. IEEE Trans. Power Electron., 14, 670-679.

[15] Hava, A. M., Kerkman, R., \& Lipo, T. A. (1998). Carrier-based PWM-VSI overmodulation strategies: Analysis, comparison, and design. IEEE Trans. Power Electron., 13, 674-689.

[16] Holmes, D. G., \& McGrath, B. P. (2001). Opportunities for harmonic cancellation with carrier-based PWM for two-level and multilevel cascaded inverters. IEEE Trans. Ind. Applicat., 37, 574 -582.

[17] Asghari, B., \& Dinavahi, V. (Nov. 2012). Experimental validation of a geometrical nonlinear permeance network based real-time induction machine model. IEEE Transactions on Industrial Electronics, 59(11), 4049-4062.

[18] Marandi, J., Pak, V.-F., \& Venkata, D. (2010). Real-time simulation of grid-connected wind farms using physical aggregation. IEEE Transactions on Industrial Electronics, 57(9), 3010.

[19] Sattar, A., Al-Durra, A., \& Muyeen, S. M. (2011). Real time implementation of STATCOM to analyze transient and dynamic characteristics of wind farm. Proceedings of 37th Annual Conference of the IEEE Industrial Electronics Society. Melbourne, Australia.

[20] Sattar, A., Al-Durra, A., \& Muyeen, S. M. (October 2011). Dynamic characteristics analysis of wind farm integrated with STATCOM using RTDS. Proceedings of 11th International Conference IEEE EPQU. Lisbon, Portugal.

[21] Kuffel, R., Giesbrecht, J., Maguire, T., Wierckx R. P., \& McLaren, P. G. (1995). RTDSA fully digital power system simulator operating in real time. Proceedings IEEE WESCANEX: Vol. 2 (p. 300).

[22] Park, M., Hwang, C., Song, B. M., \& Lee, K. Y. (2011). Voltage transient analysis of a PMSG wind power system using controller-hardware-in-the loops. Proceedings of IEEE 2011 PES Conf. of Innovation Smart Grid Technologies.

[23] Song, B. M., Hwang, C., \& Park, M. (2011). Analysis of voltage faults in the grid-connected inverter of a wind power generation system using real-time digital simulator. Proceedings of IEEE 8th International Conference on Power Electronics.

[24] Sebastian, T., \& Slemon, G. R. (Sep. 1986). Transient modeling and performance of variable-speed permanent-magnet motors. IEEE Trans. Industry Applications, 25(1), 101-106. 
[25] Dehkordi, A. B., Gole, A. M., \& Maguire, T. L. (2005). Permanent magnet synchronous machine model for real-time simulation. Proceedings of Int. Conf. Power Systems Transients.

[26] Heier, S. (1998). Grid Integration of Wind Energy Conversion Systems. Wiley.

[27] Wasynczuk, O., Man, D. T., \& Sullivan, J. P. (1981). Dynamic behavior of a class of wind turbine generator during random wind fluctuations. IEEE Trans. Power App. Syst., PAS-100, 2873.

[28] Slootweg, J. G., De Hann, S. W. H., Polinder, H., \& Kling, W. L. (2003). General model for representing variable speed wind turbines in power system dynamic simulations. IEEE Trans. Power Syst., 18, 144.

[29] Muyeen, S. M., Takahashi, R., Murata, T., Tamura, J., \& Ali, M. H. (2007). Transient stability analysis of permanent magnet variable speed synchronous wind generator. Proceedings of Int. Conf. Electr. Mach. Syst. (p. 288).

[30] Qiao, W., Venayagamoorthy, G. K., \& Harley, R. G. (2009). Real-time implementation of a STATCOM on a wind farm equipped with doubly fed induction generators. IEEE Trans. Ind. Appl., 45(1), 1073-1080.

[31] Park, M., \& Yu, I. (2004). A novel real-time simulation technique of photovoltaic generation systems using RTDS. IEEE Trans. Energy Convers., 19, 164.

[32] Park, D.-J., Kim, Y.-J., Ali, M. H., Park, M., \& Yu, I.-K. (Oct. 2007). A novel real time simulation method for grid-connected wind generator system by using RTDS. Proceedings of 2007 ICEMS International Conference on Electrical Machines and Systems (pp. 1936-1941).

[33] RTDS Technologies. (2009). Real time digital simulator power system and control user manual.

[34] IEEE. (Apr. 1993). IEEE Recommended Practices and Requirements for Harmonic Control in Electrical Power Systems. Standard 519-1992.

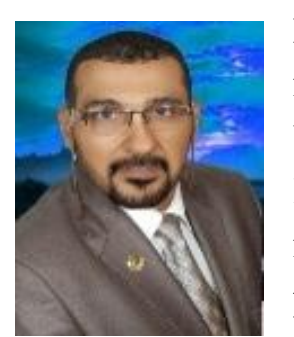

Muhammad M. A. S. Mahmoud was born in Kuwait in 1963. He received the B.S. degree in electrical engineering from Cairo University and the M.Sc. degree from Kuwait University. He received his First Ph.D. degree from Transilvania University of Brasov, Romania in IT and computer, second Ph.D. degree in electrical power system and machine, from Cairo Univ. Egypt. He occupies a position of senior electrical engineer, skill pool expert-electrical and co-chairman $\mathrm{PhD}$ council at Al Hosn Gas Co. His current research interests in fuzzy and artificial neural network techniques application include power delivery, protection reliability, control and safety. Dr. Muhammad was an IEEE Member in 1999 and became a senior member since 2001.

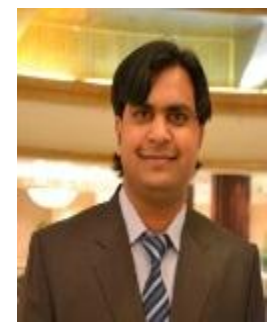

Adnan Sattar was born in Wah Cantt, Pakistan, he received his B.Sc. degree in electrical and electronics engineering from the Islamic University of Technology (IUT), Dhaka in 2008, M.Sc. degree in electrical engineering in 2012 from PI UAE. He is a member of IEEE since 2012. Currently he is working as an electrical engineer in Projects Department, Al Hosn Gas, UAE. 